\title{
Synthesis and Characterization of Thermally Stable Polymers through Anionic Polymerization of tert-Alkyl Crotonates
}

\author{
Akikazu Matsumoto, Atsushi Horie, and Takayuki Otsu* \\ Department of Applied Chemistry, Faculty of Engineering, Osaka City University, \\ Sugimoto, Sumiyoshi-ku, Osaka 558, Japan
}

(Received October 25, 1990)

\begin{abstract}
Some alkyl crotonates bearing tert-alkyl groups, i.e., tert-butyl, tert-amyl, 1-adamantyl and 3,5-dimethyl-1-adamantyl crotonates were prepared and polymerized with sec-butyllithium as an anionic catalyst in toluene or THF. The resulting polymers were confirmed to consist of poly(substituted methylene) structure by IR and NMR spectroscopies. The polymers bearing adamantyl groups had more resistance to hydrolysis, whereas the tert-butyl and amyl esters were readily hydrolyzed. The introduction of the adamantyl groups also increased glass transition temperature and decomposition temperature of the polymer. It was revealed that the polymers bearing the tert-butyl and amyl esters decomposed via a two-step mechanism, resulting in the formation of poly(crotonic acid) accompanied with elimination of corresponding olefins from the ester groups, but the polymers containing adamantyl groups showed excellent thermal stability.

KEY WORDS tert-Alkyl Crotonate / 1-Adamantyl Crotonate / 3,5-Dimethyl-1-adamantyl Crotonate / Anionic Polymerization / Poly(substituted methylene) / Hydrolysis / Glass Transition Temperature / Thermogravimetric Analysis / Thermolysis /
\end{abstract}

We have reported that dialkyl fumarates bearing bulky alkyl groups polymerize in the presence of a radical initiator to give high molecular weight polymers which consist of a poly(substituted methylene) structure (eq 1). ${ }^{1,2}$

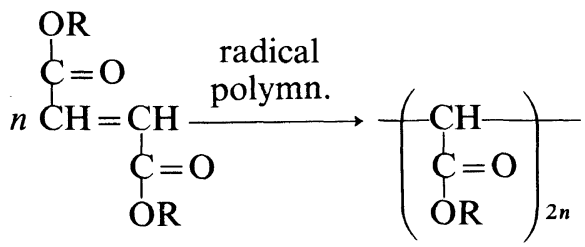

These polymers have a lessflexible structure because they have no methylene group as a spacer in the main chain, and are expected to show new properties different from ordinary flexible vinyl polymers. ${ }^{2-7}$ Polymers with a similar structure can be also obtained by polymerization of $\beta$-substituted acrylic esters such as alkyl crotonàtes ( $\mathrm{RCr}$ ) (eq 2), which give poly(substituted methylene) bearing alter- natingly methyl and alkoxycarbonyl groups as a substituent.

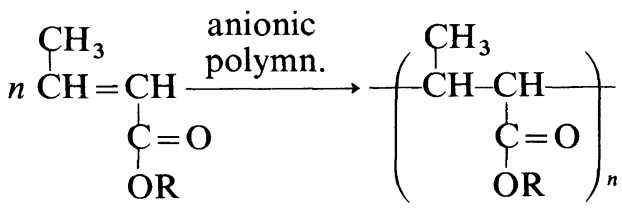

$\mathrm{RCr}$ does not proceed radical polymerization on account of steric hindrance and degradative chain transfer due to the existence of the $\beta$-methyl group, and it has been also reported that anionic high polymerization of $\mathrm{RCr}$ with methyl or $n$-alkyl esters is difficult because of the occurrence of side reactions in preference to propagation, when Grignard reagents, alkyllithiums, and $\mathrm{LiAlH}_{4}$ are used as an initiator. ${ }^{8}$ On the contrary, high molecular weight poly( $\mathrm{RCr}$ ) was obtained in polymerization of $\mathrm{RCr}$ with bulky sec- and tert-alkyl esters. ${ }^{9,10}$ Nagasawa and coworkers studied on the 

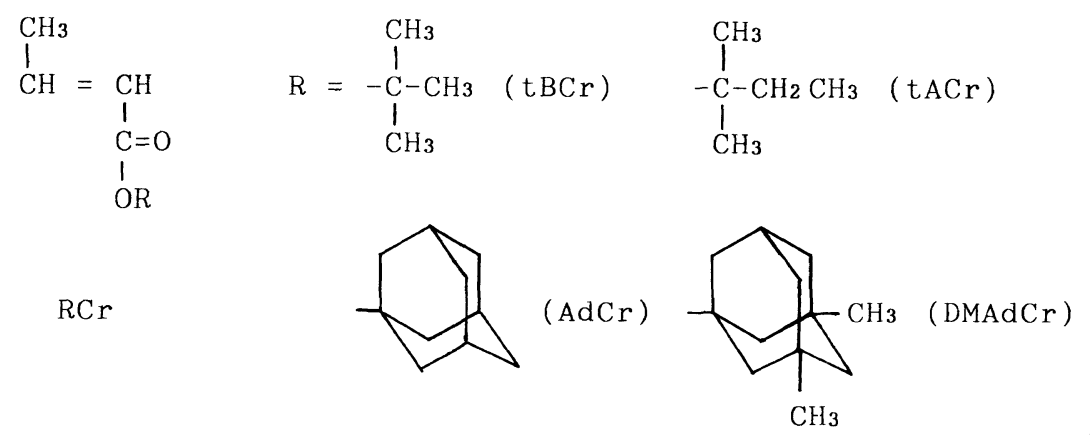

Scheme 1

synthesis of poly(tert-butyl crotonate) with a semiflexible backbone and a narrow molecular weight distribution by anionic polymerization with very careful procedures for purification and polymerization, ${ }^{11}$ and they examined as to the rigidity of the polymer chain from molecular characteristics in dilute solution or in bulk. ${ }^{12}$ However, polymerizations of other tert-alkyl esters of $\mathrm{RCr}$ have not been ever reported.

Recently, we have commenced the study on synthesis and characterization of polymers containing adamantyl groups. The introduction of an adamantyl moiety was found to induce great advancement of thermal property of the polymers because adamantane is a thermodynamically stable and highly symmetrical tricyclic hydrocarbon, which consists of fused chair-form cyclohexane rings with same structure as a diamond lattice. ${ }^{13}$ For example, polymers from 1-adamantyl or 3,5-dimethyl-1adamantyl esters of methacrylate and acrylate have extremely high glass transition temperatures and decomposition temperature. ${ }^{14}$ Other polymers bearing adamantyl moiety in the main or side chain have been also developed by some workers. ${ }^{15}$

In this study, therefore, anionic polymerization of RCr bearing tert-alkyl groups, i.e., tert-butyl, tert-amyl, 1-adamantyl, and 3,5dimethyl-1-adamantyl (Scheme 1) was performed with sec-butyllithium (sBuLi) as an initiator in toluene or THF, and the resulting polymers were characterized on the structure, hydrolysis and thermal properties.

\section{EXPERIMENTAL}

\section{Materials}

$\mathrm{tBCr}$ was commercially available. $\mathrm{tACr}$ was prepared from crotonic acid and 2-methyl-2butene with an acidic catalyst at a room temperature, or from crotonyl chloride and tert-amyl alcohol at $0^{\circ} \mathrm{C}$. $\mathrm{AdCr}$ and $\mathrm{DMAdCr}$ were obtained from crotonic acid with 1-hydroxyadamantane and 1,3-dimethyl-5-hydroxyadamantane, respectively, which were supplied from Hakusui Chemical Industries Co., Ltd., in cyclohexane in the presence of sulfuric acid with reflux for $7 \mathrm{~h}$.

AdCr: Yield $84 \%$, bp $95^{\circ} \mathrm{C} / 1 \mathrm{mmHg}, d_{20}$ $1.058, n_{\mathrm{D}}^{24} 1.506$; IR (neat) $v_{\mathrm{C}=\mathrm{O}} 1710, v_{\mathrm{C}=\mathrm{C}}$ $1650 \mathrm{~cm}^{-1},{ }^{13} \mathrm{C}$ NMR $\left(\mathrm{CDCl}_{3}\right) \delta 165.2,142.5$, $124.5,79.5,41.1,36.0,30.6$, and $17.4 \mathrm{ppm}$; ${ }^{1} \mathrm{H}$ NMR $\left(\mathrm{CDCl}_{3}\right) \delta 6.85(\mathrm{dq}, J=15.6 \mathrm{~Hz}$ and $\left.6.7 \mathrm{~Hz}, 1 \mathrm{H}, \mathrm{CH}_{3} \mathrm{CH}=\mathrm{CH}\right), 5.76(\mathrm{dq}, J=15.6$ $\mathrm{Hz}$ and $\left.1.8 \mathrm{~Hz}, 1 \mathrm{H}, \mathrm{CH}_{3} \mathrm{CH}=\mathrm{CH}\right), 2.16(\mathrm{br}$, $3 \mathrm{H}, \mathrm{CH}$ (adamantyl)), 2.14 (br, 6H, $\mathrm{CH}_{2}$ (adamantyl)), $1.84(\mathrm{dd}, J=6.7 \mathrm{~Hz}$ and $1.8 \mathrm{~Hz}, 3 \mathrm{H}$, $\left.\mathrm{CH}_{3} \mathrm{CH}=\mathrm{CH}\right)$, and $1.67 \mathrm{ppm}\left(\mathrm{br}, 6 \mathrm{H}, \mathrm{CH}_{2}\right.$ (adamantyl)).

DMAdCr: Yield $80 \%$, bp $124^{\circ} \mathrm{C} / 0.9 \mathrm{mmHg}$, $d_{20} 1.025, n_{\mathrm{D}}^{24} 1.493 ;$ IR (neat) $v_{\mathrm{C}=\mathrm{O}} 1710, v_{\mathrm{C}=\mathrm{C}}$ $1650 \mathrm{~cm}^{-1} ;{ }^{13} \mathrm{C}$ NMR $\left(\mathrm{CDCl}_{3}\right) \delta 165.7,143.0$, $124.6,81.4,50.5,47.3,42.5,39.8,33.8,31.1$, 29.9, and $17.7 \mathrm{ppm} ;{ }^{1} \mathrm{H}$ NMR $\left(\mathrm{CDCl}_{3}\right) \delta 6.84$ 
(dq, $J=15.6 \mathrm{~Hz}$ and $6.7 \mathrm{~Hz}, 1 \mathrm{H}, \mathrm{CH}_{3} \mathrm{CH}=$ $\mathrm{CH}), 5.75(\mathrm{dq}, J=15.6 \mathrm{~Hz}$ and $1.8 \mathrm{~Hz}, 1 \mathrm{H}$, $\left.\mathrm{CH}_{3} \mathrm{CH}=\mathrm{CH}\right), 1.83(\mathrm{dd}, J=6.7 \mathrm{~Hz}$ and $1.8 \mathrm{~Hz}$, $\left.3 \mathrm{H}, \mathrm{CH}_{3} \mathrm{CH}=\mathrm{CH}\right), 1.1-2.2(\mathrm{~m}, 13 \mathrm{H}$, adamantyl), and $0.8 \mathrm{ppm} \mathrm{(s,} \mathrm{6H,} \mathrm{CH}_{3}$ (adamantyl)).

RCrs were distilled under a reduced pressure over calcium hydride or triethylaluminum before use. ${ }^{16}$ Commercial sBuLi $\left(1.0 \mathrm{~mol}^{-1}\right.$ in cyclohexane, Kanto Chemical Co., Tokyo) was used without further purification. Other reagents and solvents were purified by ordinary methods.

\section{Polymerization Procedures}

All procedures for transfer of materials were carried out under dry nitrogen atmosphere by using a Y-shaped glass tube with a rubbery cap and a hypodermic syringe. Polymerization was performed under vacuum and stopped with methanol containing hydrochloric acid. Polymer was precipitated with a large amount of methanol, filtered, and dried under vacuum.

\section{Hydrolysis and Methylation}

Poly( $\mathrm{RCr}$ ) was hydrolyzed in chloroform in the presence of a catalytic amount of $\mathrm{H}_{2} \mathrm{SO}_{4}$ with reflux for $24 \mathrm{~h}$, or in concentrated $\mathrm{H}_{2} \mathrm{SO}_{4}$ at room temperature for 5 days. The resulting poly(crotonic acid) was isolated by pouring into a large amount of water after the solvent was removed. Then it was reprecipitated from methanol and diethyl ether.

Poly(crotonic acid) was converted to the methyl ester by reflux in methanol in the presence of an acidic catalyst for $24 \mathrm{~h}$, followed by the reaction with diazomethane. The polymer obtained was purified by reprecipitation from benzene and methanol.

\section{Measurements}

IR spectra were recorded on a JASCO A202 spectrometer. NMR spectra were taken by means of JEOL GX-400 in $\mathrm{CDCl}_{3}$ at an ambient temperature. Gel permeation chromatography (GPC) was carried out with THF as eluent at $38^{\circ} \mathrm{C}$, and number- and weightaverage molecular weights $\left(\bar{M}_{n}\right.$ and $\left.\bar{M}_{w}\right)$ were calibrated with standard polystyrenes. Differential scanning calorimetry (DSC) and thermogravimetric analysis (TGA) were carried out in a nitrogen stream with a heating rate of $10^{\circ} \mathrm{Cmin}^{-1}$.

\section{RESULTS AND DISCUSSION}

\section{Anionic Polymerization}

The results of anionic polymerzation of $\mathrm{RCr}$ with sBuLi are shown in Table I. In polymerization of $\mathrm{tBCr}$ in toluene, a high molecular weight polymer was obtained with a high yield, but its molecular weight distribution (MWD) was relatively broad $\left(\bar{M}_{w} / \bar{M}_{n}>2\right)$. The use of THF as a solvent resulted in the achievement of fast polymerization at $-78^{\circ} \mathrm{C}$. Furthermore, the resulting poly (tBCr) was found to have a considerably narrow MWD $\left(\bar{M}_{w} / \bar{M}_{n}<1.2\right)$, although the initiation efficiency was low. These results were in good agreement with the results previously reported by Kitano et al. ${ }^{11}$

In polymerization of $\mathrm{AdCr}$ in toluene, the polymer yield was very low even at $0^{\circ} \mathrm{C}$, but addition of $N, N, N^{\prime}, N^{\prime}$-tetramethylethylenediamine (TMEDA) was effective for increasing of the polymer yield. The polymerization of $\mathrm{AdCr}$ in THF yielded the polymer quantitatively, as well as the polymerization of $\mathrm{tBCr}$. However, the moderately broad MWD of the resulting poly(AdCr) $\left(\bar{M}_{w} / \bar{M}_{n} \sim 1.5\right)$ was different from the case of polymerization of $\mathrm{tBCr}$. Recently, we found that low dispersity polymer was obtained when the polymerization of $\mathrm{AdCr}$ was carried out in the presence of lithium chloride $(\mathrm{LiCl}),{ }^{17}$ although its polymerization rate decreased drastically.

Since 1,2-disubstituted ethylenes including $\mathrm{RCr}$ are generally low-reactive because of the steric hindrance of the $\beta$-substituent, the contribution of unfavorable side reactions, e.g., carbonyl attack and metalation at the $\alpha$ position may be more important during 
Table I. Anionic polymerization of $\mathrm{RCr}$ in toluene or THF with $\mathrm{sBuLi}$

\begin{tabular}{|c|c|c|c|c|c|c|c|}
\hline Monomer & sBuLi & Solvent & Temp. & Time & Yield $^{a}$ & & \\
\hline $\mathrm{mmol}$ & $\mathrm{mmol}$ & $\mathrm{ml}$ & ${ }^{\circ} \mathrm{C}$ & $\mathrm{h}$ & $\%$ & & \\
\hline $\operatorname{tBCr}(13.6)$ & 0.88 & Toluene (8.3) & -78 & 28 & 48.1 & 112000 & 2.75 \\
\hline $\mathrm{tBCr}(13.6)$ & 0.88 & Toluene (8.3) & 0 & 28 & 95.9 & $-^{\mathrm{c}}$ & $-^{\mathrm{c}}$ \\
\hline $\operatorname{tBCr}(13.6)$ & 0.87 & THF (15) & -78 & 1 & 80.2 & 11300 & 1.17 \\
\hline $\operatorname{tBCr}(13.6)$ & 0.87 & THF (15) & -78 & 2 & 95.8 & 20200 & 1.21 \\
\hline $\mathrm{tACr}(8.32)$ & 0.61 & THF (1.8) & -78 & 50 & 28.8 & 11800 & 1.54 \\
\hline $\operatorname{AdCr}(10.9)$ & 0.87 & Toluene (56) & -78 & 3 & 0.6 & - & - \\
\hline AdCr (10.9) & $0.87^{\mathrm{d}}$ & Toluene (56) & -78 & 3 & 73.9 & 45000 & 3.48 \\
\hline $\operatorname{AdCr}(10.9)$ & 0.87 & Toluene (56) & 0 & 3 & 16.1 & 11000 & 3.38 \\
\hline AdCr (9.44) & 0.87 & THF (56) & -78 & 0.5 & 84.0 & 5200 & 1.48 \\
\hline $\operatorname{AdCr}(10.9)$ & 0.87 & THF (56) & -78 & 1 & 99.1 & 8100 & 1.58 \\
\hline $\operatorname{AdCr}(9.44)$ & $0.87^{e}$ & THF (56) & -78 & 4 & 11.6 & 1900 & 1.20 \\
\hline DMAdCr (9.26) & 0.87 & THF (56) & -78 & 1 & 74.7 & 11200 & 1.80 \\
\hline
\end{tabular}

a Methanol-insoluble polymer.

b Determined by GPC.

c Insoluble in THF.

d TMEDA (0.91 mmol) was added.

e $\mathrm{LiCl}(2.6 \mathrm{mmol})$ was added.

polymerization. More detail investigations on anionic polymerization of $\mathrm{RCr}$ with several alkyllithiums and on the effects of the additives such as TMEDA or $\mathrm{LiCl}$ are now continued.

\section{Structure of Poly $(R C r)$}

All poly(RCr)s obtained were colorless powder, and were soluble in benzene, THF, chloroform and insoluble methanol and $n$-hexane. In Figures $1-3$, IR, ${ }^{13} \mathrm{C}$, and ${ }^{1} \mathrm{H}$ NMR spectra of AdCr and poly(AdCr) are shown, respectively. The absorption due to a carbon-to-carbon double bond did not observed in the spectra of the polymer. Thus it was verified that these polymerization proceeded via an opening of the double bond to yield a poly(substituted methylene), i.e., poly(methylmethylene-alt-alkoxycarbonylmethylene).

\section{Hydrolysis of Poly $(\mathrm{RCr})$}

Poly(tBCr) and poly(tACr) were readily hydrolyzed by an acidic catalyst; e.g., poly(crotonic acid) (poly(CrA)) was obtained quantitatively by reflux in chloroform in the presence of sulfuric acid. The resulting

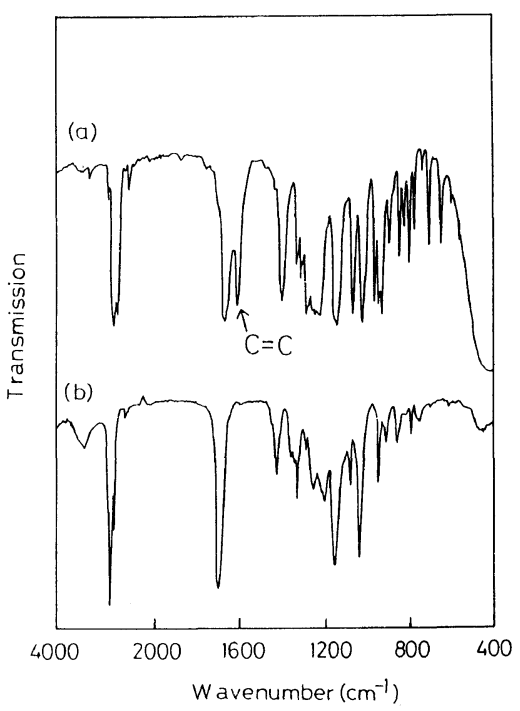

Figure 1. IR spectra of (a) $\mathrm{AdCr}$ and (b) poly(AdCr).

poly $(\mathrm{CrA})$ was soluble in methanol and alkaline water, and insoluble in many organic solvents. The IR spectrum of poly $(\mathrm{CrA})$ obtained by hydrolysis is shown in Figure 4(a).

On the other hand, the polymers bearing an adamantyl group were found to show resistant 

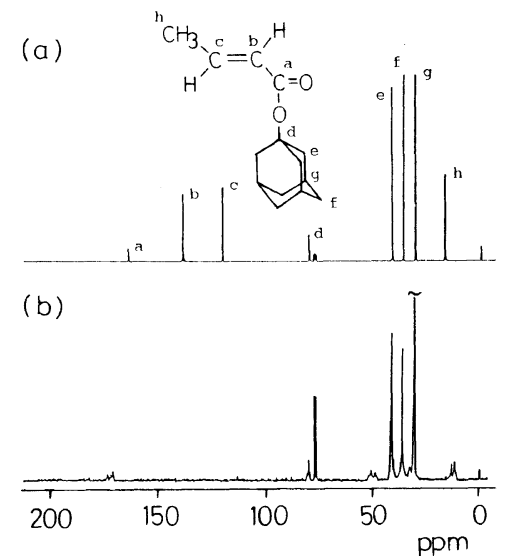

Figure 2. ${ }^{13} \mathrm{C}$ NMR spectra of (a) $\mathrm{AdCr}$ and (b) poly $(\mathrm{AdCr})$ in $\mathrm{CDCl}_{3}$.

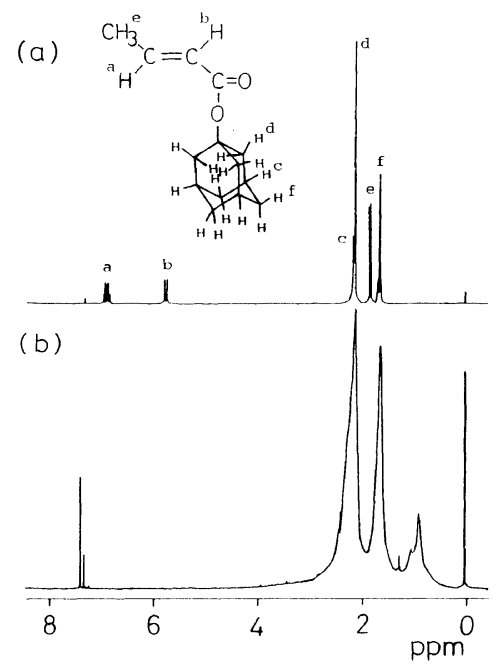

Figure 3. ${ }^{1} \mathrm{H}$ NMR spectra of (a) $\mathrm{AdCr}$ and (b) poly(AdCr) in $\mathrm{CDCl}_{3}$.

to hydrolysis; i.e., a partly hydrolyzed polymer was only recovered from poly( $\mathrm{AdCr})$ under the similar conditions (Figure 4(b)). Therefore more severe conditions were required to achieve quantitative hydrolysis of poly $(\mathrm{AdCr})$. Figure 4(c) shows the IR spectrum of poly $(\mathrm{CrA})$ isolated from hydrolysis of poly(AdCr) in concentrated sulfuric acid. It was identical to that of poly $(\mathrm{CrA})$ obtained from poly(tBCr) above.

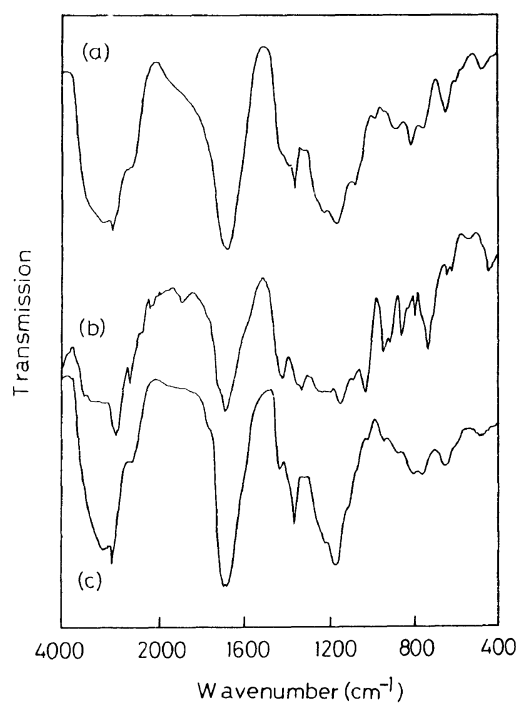

Figure 4. IR spectra of poly $(\mathrm{CrA})$ obtained by hydrolysis with an acidic catalyst from (a) poly(tBCr), reflux in $\mathrm{CHCl}_{3}$, (b) poly(AdCr), reflux in $\mathrm{CHCl}_{3}$, (c) poly(AdCr), conc. $\mathrm{H}_{2} \mathrm{SO}_{4}$, room temp.

\section{Thermal Properties}

Thermal properties of poly( $\mathrm{RCr})$ obtained were investigated. The $T_{g}$ of poly $(\mathrm{AdCr})$ was not observed under its decomposition temperature, but poly(DMAdCr) showed a small transition at $230^{\circ} \mathrm{C}$ in the DSC thermogram. Recently, we found that $T_{g}$ of poly(1adamantyl methacrylate) was over its decomposition temperature, but its 3,5-dimethyl substituted derivative had $T_{\mathrm{g}}$ of $194^{\circ} \mathrm{C} .{ }^{14}$ The marked increase in $T_{\mathrm{g}}$ by the introducing of an adamantyl moiety into polymers was reported also for other polymers. ${ }^{15}$ Moreover, the higher $T_{\mathrm{g}}$ of poly(DMAdCr) rather than the corresponding polymethacrylate may be ascribed to the lessflexible poly(substituted methylene) structure.

Figure 5 shows the results of TGA for poly $(\mathrm{RCr})$ in a nitrogen stream. The initial decomposition temperature $\left(T_{\text {init }}\right)$ and the maximum decomposition temperature $\left(T_{\max }\right)$ are summarized in Table II. In the thermograms for poly $(\mathrm{tBCr})$ and poly(tACr), a rapid weight-loss was observed around $200^{\circ} \mathrm{C}$, and decomposition proceeded via two or more 
steps. The first weight-loss was considered to be due to elimination of olefins from tert-alkyl group of the side chain (Scheme 2). ${ }^{18-20}$

The residual weights of the polymers after

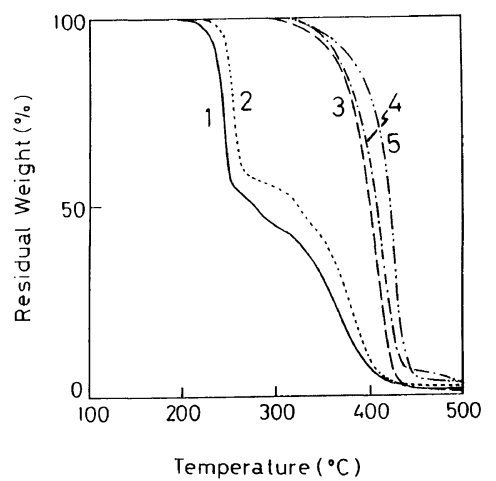

Figure 5. Thermogavimetric analysis of poly $(\mathrm{RCr})$ in a nitrogen stream at a heating rate of $10^{\circ} \mathrm{Cmin}^{-1}$; (1) poly(tACr), (2) poly(tBCr), (3) poly $(\mathrm{MCr})$, (4) poly(DMAdCr), (5) poly(AdCr).

Table II. Thermogravimetric analysis for poly $(\mathrm{RCr}) \mathrm{s}^{\mathrm{a}}$

\begin{tabular}{lcc}
\hline \multirow{2}{*}{ Polymer } & $T_{\text {init }}$ & $T_{\max }{ }^{\mathrm{b}}$ \\
\cline { 2 - 2 } & ${ }^{\circ} \mathrm{C}$ & ${ }^{\circ} \mathrm{C}$ \\
\hline Poly(tBCr) & 219 & $260(279)(318)(378)$ \\
Poly(tACr) & 206 & $250(285)(372)$ \\
Poly(AdCr) & 305 & 428 \\
Poly(DMAdCr) & 308 & 418 \\
Poly(MCr) & 267 & 400 \\
\hline
\end{tabular}

a In a nitrogen stream with a heating rate of $10^{\circ} \mathrm{Cmin}^{-1}$.

b The values in parentheses indicate the peaks other than the $T_{\max }$ in the differential curves. the first-step decomposition were $58.5 \%$ $\left(275^{\circ} \mathrm{C}\right)$ and $53.6 \%\left(265^{\circ} \mathrm{C}\right)$ for poly $(\mathrm{tBCr})$ and poly(tACr), respectively, agreeing with the values calculated with quantitative elimination of isobutene or 2-methyl-1-butene and 2methyl-2-butene, respectively. The subsequent weight-loss peak due to the formation of an anhydride ring between the resulting carboxylic acids was observed around $300^{\circ} \mathrm{C}$, but it seemed that the scission of the main chain also occurred concurrently.

To confirm the formation of poly $(\mathrm{CrA})$, poly(tACr) was heated at $200^{\circ} \mathrm{C}$ under vacuum. The weight of the residual polymer decreased rapidly within an initial few hours, and then kept almost constant. In the IR spectra of the polymer isolated after heating (Figure 6), the characteristic absorption due to a carboxylic acid was observed. The absorption of anhydride consisting of a 6-membered ring was also observed at 1800 and $1750 \mathrm{~cm}^{-1}$ in the spectra when it was heated for a long period.

On the other hand, poly(AdCr) and poly(DMAdCr) were revealed to have an excellent thermal stability, i.e., $T_{\text {init }}>300^{\circ} \mathrm{C}$ and $T_{\max } \sim 420^{\circ} \mathrm{C}$. These polymers containing adamantyl groups were thermally stable more than the polymer bearing a primary alkyl group, e.g., poly(methyl crotonate) (poly(MCr)) which is derived by esterification of poly $(\mathrm{CrA})$ as mentioned later. The high performance of these polymers may be originated from the stable 1-adamantyl esters which evolve hardly a corresponding olefin because of their rigid

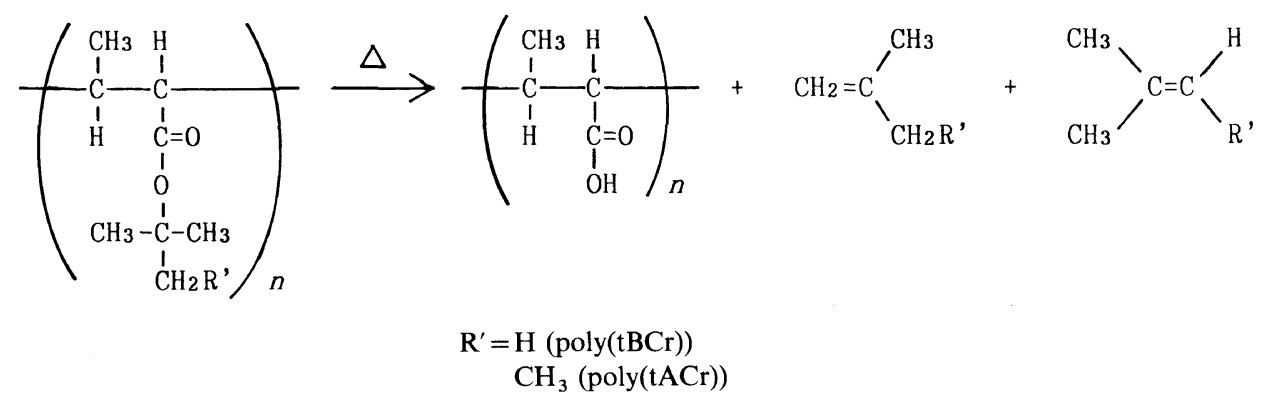

Scheme 2 


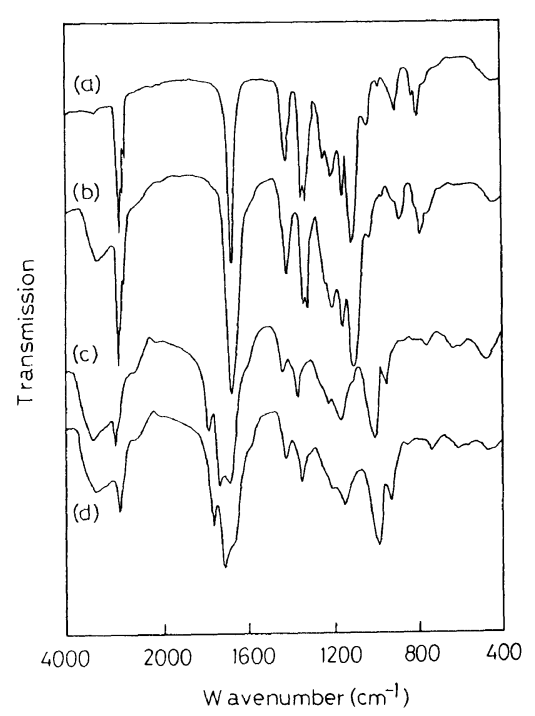

Figure 6. IR spectra of the polymers recovered after for pyrolysis of poly(tACr) in vacuum at $200^{\circ} \mathrm{C}$ for (a) 0 , (b) 45 , (c) 165 , (d) $285 \mathrm{~min}$.

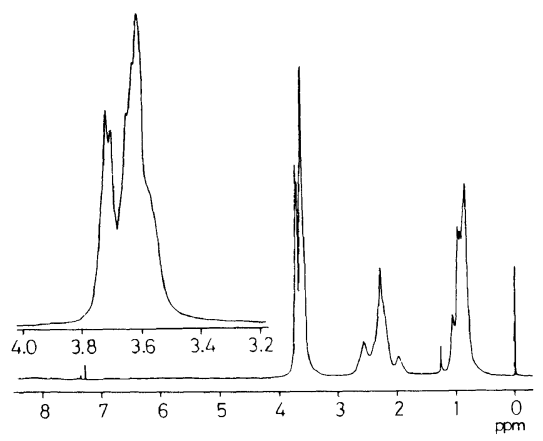

Figure 7. ${ }^{1} \mathrm{H}$ NMR spectrum of poly(MCr) derived from $\operatorname{poly}(\mathrm{CrA})$.

and stable skeleton. ${ }^{13,21}$

Poly(MCr) was obtained by methylation of poly(CrA). In the ${ }^{1} \mathrm{H}$ NMR spectrum of the resulting poly(MCr) (Figure 7), the methoxy proton was clearly observed as multiplet. This splitting of the methoxy proton signal may be useful for determination of the configuration of poly( $\mathrm{RCr}),{ }^{8}$ as well as ${ }^{13} \mathrm{C}$ NMR spectroscopy. ${ }^{22}$ A study on tacticity of the polymers from $\beta$-substituted acrylic esters is important in order to clarify a mechanism and reactivity of the polymerization of 1,2- disubstituted ethylenes. ${ }^{4}$ The structure and properties of poly(substituted methylene)s are of great interest for us, and further investigations on the tacticity of poly $(\mathrm{RCr})$ are also now in progress.

Acknowledgments. A part of this work was supported by Grant-in-Aids for Scientific Research (No. 01430019) from the Ministry of Education, Science and Culture, Japan, and from Izumi Science and Technology Foundation. The authors are also greatly indebted to Hakusui Chemical Industries Co., Ltd. for supply of 1-hydroxyadamantane and 1,3dimethyl-5-hydroxyadamantane, and to $\mathrm{Mr}$. Shigeki Mori, Osaka City University, for TGA measurements.

\section{REFERENCES}

1. T. Otsu, O. Ito, N. Toyoda, and S. Mori, Makromol. Chem., Rapid Commun., 2, 725 (1981).

2. T. Otsu, T. Yasuhara, and A. Matsumoto, J. Macromol. Sci.-Chem., A25, 537 (1988), and references therein.

3. A. Matsumoto, T. Tarui, and T. Otsu, Macromolecules, 23, 5102 (1990).

4. M. Yoshioka, A. Matsumoto, T. Otsu, and I. Ando, Polymer, in press.

5. A. Matsumoto, Y. Oki, and T. Otsu, Makromol. Chem., Rapid Commun., 11, 507 (1990).

6. H. Ikebe, Y. Murata, and T. Otsu, Polym. Prepr., Jpn., 34, 420 (1985).

7. S. B. Choi, A. Takahara, N. Amaya, Y. Murata, and T. Kajiyama, Polym. J., 21, 433 (1989).

8. T. Tsuruta, T. Makimoto, and T. Miyazako, Makromol. Chem., 103, 128 (1967); T. Tsuruta, T. Makimoto, and K. Tanabe, ibid., 114, 182 (1968).

9. M. L. Miller and J. Skogman, J. Polym. Sci., A, 2, 4551 (1964).

10. R. K. Graham, J. E. Moore, and J. A. Powell, J. Appl. Polym. Sci., 11, 1797 (1967).

11. T. Kitano, T. Fujimoto, and M. Nagasawa, Macromolecules, 7, 719 (1974); T. Kitano, M. Mitsumura, T. Fujimoto, and M. Nagasawa, ibid., 8, 382 (1975).

12. I. Noda, T. Imai, T. Kitanio, and M. Nagasawa, Macromolecules, 14, 1303 (1981); I. Noda, Y. Yamamoto, T. Kitano, and M. Nagasawa, ibid., 14, 1306 (1981); Y. Muroga, I. Sakuragi, I. Noda, and M. Nagasawa, ibid., 17, 1844 (1984). 
13. H. Stetter, Angew. Chem., 74, 361 (1962); R. C. Font, Jr., P. von R. Schleyer, Chem. Rev., 64, 277 (1964).

14. A. Matsumoto, S. Tanaka, and T. Otsu, to be published.

15. For example; H. F. Reinhart, Polym. Lett., 2, 367 (1964); US Patent 3342880 (1967); M. E. Hoagland and I. N. Duling, Division of Petroleum Chemistry, 159 th ACS Meeting, Preprint, 15(2), B85 (1970); S. Moon, A. L. Schwartz, J. K. Hecht, J. Polym. Sci., $A-1,8,3665$ (1970); S. Nozakura, T. Okamoto, K. Toyora, and S. Murahashi, J. Polym. Sci., Polym. Chem. Ed., 11, 1043 (1973); Y. Okano, T. Masuda, and T. Higashimura, ibid., 23, 2527 (1985); B. R. Hsieh and M. H. Litt, J. Polym. Sci., A, Polym. Chem., 26, 2501 (1988).

16. R. D. Allen, T. E. Long, and J. E. McGrath, Polym. Bull., 15, 127 (1986).
17. Ph. Teyssie, R. Fayt, J. P. Hautekeer, C. Jacobs, R. Jerome, L. Leemans, and S. K. Varshney, Makromol. Chem., Macromol. Symp., 32, 61 (1990); S. K. Varshney, J. P. Hautekeer, R. Fayt, R. Jerome, and Ph. Teyssie, Macromolecules, 23, 2618 (1990).

18. D. H. Grant and N. Grassie, Polymer, 1, 445 (1960).

19. T. Otsu, T. Yasuhara, K. Shiraishi, and S. Mori, Polym. Bull., 12, 449 (1984); T. Otsu, K. Shiraishi, A. Matsumoto, T. Yasuhara, N. Amaya, and S. Mori, Polym. Commun., 26, 367 (1983).

20. T. Otsu, A. Tatsumi, and A. Matsumoto, J. Polym. Sci., C, Polym. Lett., 24, 113 (1986); T. Otsu, A. Matsumoto, A. Tatsumi, Polym. Bull., 24, 467 (1990).

21. W. Burns, D. Grant, M. A. McKervey, and G. Step, J. Chem. Soc., Perkin Trans. 1, 234 (1976).

22. Y. Muroga, I. Noda, and M. Nagasawa, Macromolecules, 13, 1081 (1980). 